\title{
Variations in the Human Pulmonary Fissures and Lobes: A Cadaveric Study
}

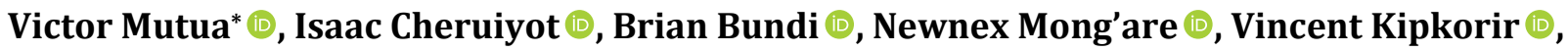 \\ Elma Othieno
}

School of Medicine, University of Nairobi, Nairobi, Kenya

Email: *vicmutua3@gmail.com

How to cite this paper: Mutua, V., Cheruiyot, I., Bundi, B., Mong'are, N., Kipkorir, V. and Othieno, E. (2021) Variations in the Human Pulmonary Fissures and Lobes: A Cadaveric Study. Open Access Library Journal, 8: e7787.

https://doi.org/10.4236/oalib.1107787

Received: July 25, 2021

Accepted: August 22, 2021

Published: August 25, 2021

Copyright $\odot 2021$ by author(s) and Open Access Library Inc.

This work is licensed under the Creative Commons Attribution International License (CC BY 4.0).

http://creativecommons.org/licenses/by/4.0/

\section{(c) (i) Open Access}

\begin{abstract}
The objective of this study was to describe the variations in human pulmonary fissuration in a cadaveric Kenyan population. Data were collected from 48 formalin-fixed cadavers in the department of Human Anatomy, University of Nairobi, Kenya; with 38 right and 32 left lungs meeting the study's inclusion criteria. The fissures were studied irrespective of the cadaver's sex and were classified anatomically as proposed by Craig and Walker (1997). Out of the 38 right lungs examined, the horizontal fissure was absent in 4 lungs (10.5\%), incomplete in 16 lungs (42.1\%), and complete in 18 lungs (47.3\%). Out of the 32 left lungs, the oblique fissure was incomplete in 11 lungs (34.4\%) and complete in 21 lungs (65.6\%). An accessory fissure was observed in 3 right lungs (7.9\%); 2 of which were inferior accessory fissures and 1 being an azygous fissure. Twelve left lungs (37.5\%) had an accessory fissure; all of which were left minor fissures. The present study details important variations in the anatomy of the human pulmonary fissure in Kenya. Knowledge and awareness of these findings are paramount, due to their implications in clinical practice, such as in the interpretation of thoracic images by radiologists and preoperative planning by thoracic surgeons.
\end{abstract}

\section{Subject Areas}

Human Anatomy, Radiology, Cardiothoracic Surgery

\section{Keywords}

Lobes, Fissures, Accessory Fissure, Accessory Lobe

\section{Introduction}

The lungs are divided into various lobes by a layer of in-folded reflections of 
visceral pleura referred to as pulmonary fissures [1]. There are two types of fissures: lobar or Major Fissure (MF) and Accessory Fissure (AF) [1]. The MF includes the oblique and horizontal fissure.

The oblique fissure divides the left lung into two lobes: superior and inferior lobes. This fissure runs from the costal to the mediastinal surface of the lung both above and below the hilum. Superficially, this fissure begins at the posterosuperior part of the hilum then ascends obliquely backwards to cross the posterior border. It further descends forward across the costal surface to reach the lower border almost at its anterior end. The left horizontal fissure is a normal variant found in $10 \%$ of patients [2] [3].

The oblique and horizontal fissure divides the right lung into 3 lobes: superior, middle and inferior lobe. The oblique fissure separates the inferior lobe from the middle and upper lobes, and corresponds closely to the left oblique fissure. The short horizontal fissure separates the superior and middle lobes. It passes from the oblique fissure, near the midaxillary line, horizontally forwards to the anterior border of the lung, level with the sternal end of the fourth costal cartilage, and passes further backwards to the hilum on the mediastinal surface. The oblique fissure is usually visible on a lateral radiograph and on a high-resolution CT scan as a curvilinear line from the lateral aspect to the hilum while the horizontal fissure is usually visible on a frontal chest radiograph [3].

An accessory fissure in the lung is a congenital variation, which occurs due to failed obliteration of the fissure separating individual bronchopulmonary segments during development [4]. The commonly found accessory fissures are the Superior Accessory Fissure (SAF), the Inferior Accessory Fissure (IAF), the Left Minor Fissure (LMF) and the azygous fissure. The SAF is seen in the territory of the lower lobe which partially or completely separates the superior segment of the lower lobe from the basal segments. The IAF is seen around the medial basal segment of the lower lobe and the fissure extends laterally and upwards towards the major fissure. An LMF separates the lingula from the rest of the left upper lobe [5] [6].

The MF is considered "complete" when the lobes remain held together only at the hilum by the bronchi and pulmonary vessels; and "incomplete" when there are areas of parenchymal fusion between the lobes [7] [8]. As major fissures form the boundaries of the pulmonary lobes, the knowledge of their normal and variant configuration is essential for recognizing their variable imaging appearances [9]. Furthermore, incomplete fissures may alter the usual patterns of the collapse of the lung seen in lobar lesions. They may also give rise to the atypical appearance of pathologic conditions, for instance, pneumonia and carcinoma in a particular lobe is often limited to that lobe by the fissures and may spread to adjacent lobes through the incomplete fissures [10]. In addition, knowledge on variations in the completeness of fissures is the key in patients with emphysema who undergo one-way valve bronchoscopic lung volume reduction. The most important factor that prevents the achievement of desired atelectasis after endobron- 
chial one-way valve treatment is interlobar collateral ventilation through an incomplete interlobar fissure [11] [12].

Variations in grading of major fissures and the presence of accessory fissures have been described and their frequencies observed to differ between populations [5] [13] [14] [15] [16]. Data from the African population are scarce and altogether absent from the Kenyan population [15]. The purpose of this study was to describe the variations in human pulmonary fissuration in a cadaveric Kenyan population

\section{Methods}

The present study was carried out in the department of Human anatomy, University of Nairobi, Kenya. Data were collected from 48 formalin-fixed Kenyan cadavers during routine undergraduate dissection. Dissection of the thorax was carried out following instructions given in the Cunningham's Manual of Practical Anatomy.

The 96 lungs were examined by two authors (V.M and V.K). Only those lungs with intact visceral pleura covering all over except at hilum were included. The lungs that were damaged during dissection, and/or with pathological lesions e.g. trauma and necrosis were excluded. Thirty eight right and 32 left lungs which met the inclusion criteria and data on variations of MF and presence of AF were recorded irrespective of the gender of the deceased. The lungs were observed for 1) presence or absence of major fissures; 2) variations in major fissures, that is, complete versus incomplete; and 3) presence and type of accessory fissure, if any. The accessory fissures that were considered in this study as illustrated in Figure 2 were: azygous fissure, Superior Accessory Fissure (SAF), Inferior Accessory Fissure (IAF), and Left Minor Fissure (LMF). The anatomical classification proposed by [7] was used to determine the presence and completeness of the major fissures (Table 1). Figures 1-3 illustrate major fissure, accessory fissure, and grading of major fissure respectively.
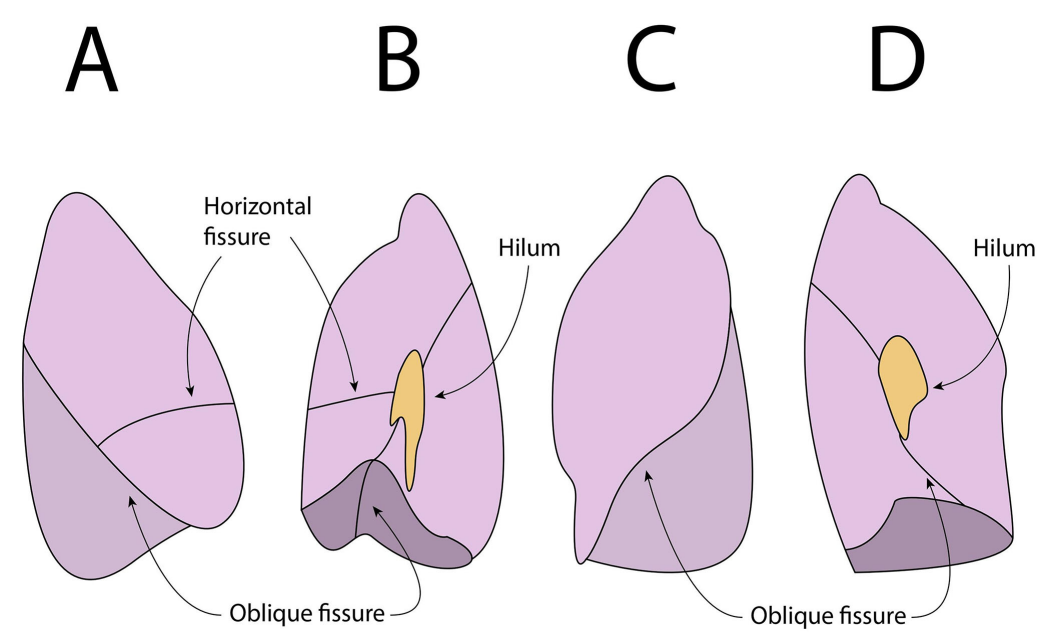

Figure 1. Schematic drawings of the lungs illustrating normal major fissures (oblique and horizontal fissures). (A, C) costal surface; (B, D) medial surface. 


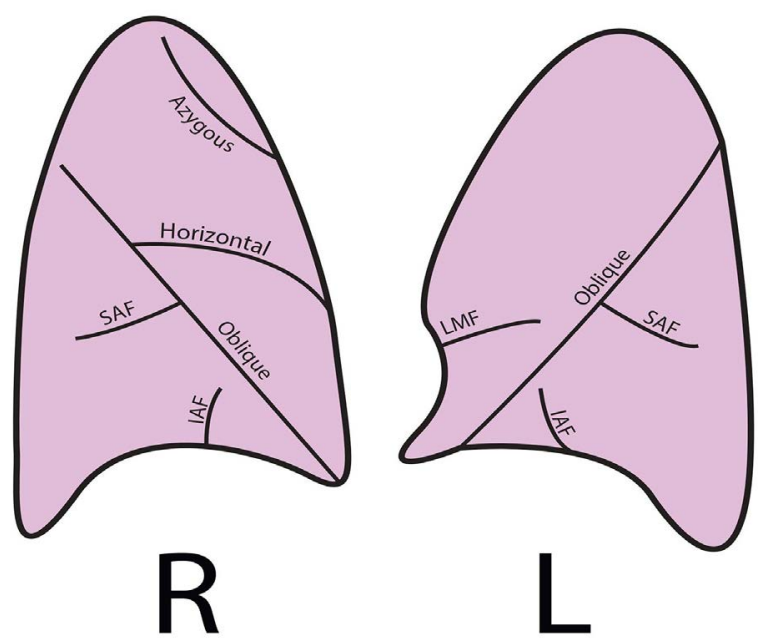

Figure 2. Schematic drawings of the lungs with the major fissures (oblique \& horizontal) and accessory fissures (SAF: superior accessory, IAF: inferior accessory, LMF: left minor \& azygous fissure).

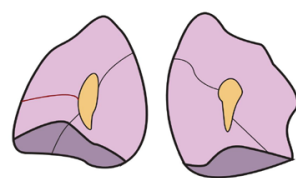

Grade I

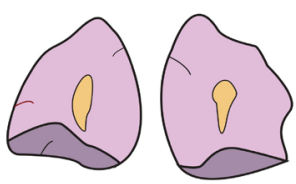

Grade III

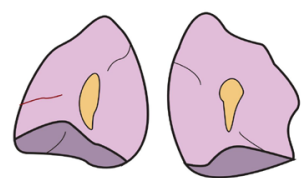

Grade II

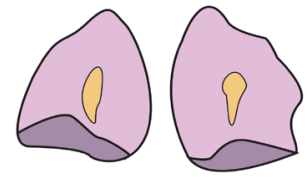

Grade IV

Figure 3. Schematic drawing illustrating the grading of fissures according to Craig and Walker classification [7].

Table 1. Grading of completeness of a fissure (Craig and Walker classification) [7].

\begin{tabular}{ccr}
\hline Complete & Grade I & Complete fissure with entirely separated lobes. \\
\hline \multirow{2}{*}{ Incomplete } & Grade II & Complete visceral cleft but parenchymal fusion at the base of fissure. \\
& Grade III & Visceral cleft evident for a part of fissure. \\
Absent & Grade IV & Complete fusion of lobes with no evident fissural line.
\end{tabular}

\section{Results}

Seventy lungs, 32 left and 38 right-sided lungs met the inclusion criteria, and were therefore included in the study. Out of the 38 right lungs examined, the horizontal fissure was absent in 4 lungs (10.5\%), incomplete in 16 lungs (42.1\%) (Figure 4) and complete in 18 lungs (47.3\%). The Oblique fissure was absent in none of the lungs (0\%), incomplete in 14 lungs (36.8\%), and complete in 24 lungs (63.1\%) (Figure $5)$.

Out of the 32 left lungs, the complete oblique fissure was noted in 21 lungs 
(65.6\%) (Figure 6), and incomplete in 11 lungs (34.4\%) (Figure 7). The observations regarding variation in the oblique, horizontal, and accessory fissures in both the right and left lungs are summarized in Table 2 .

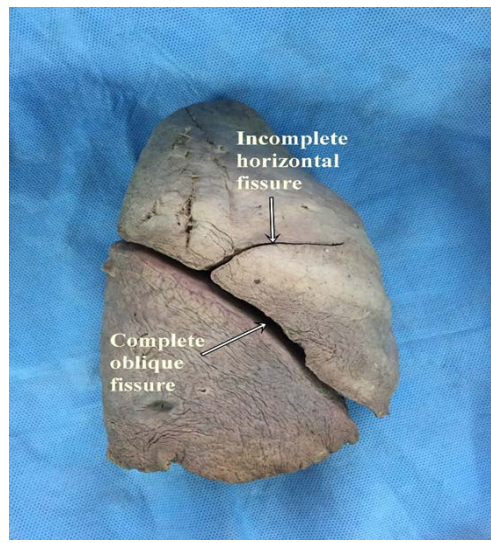

Figure 4. Right lung showing complete oblique fissure and incomplete horizontal fissure.

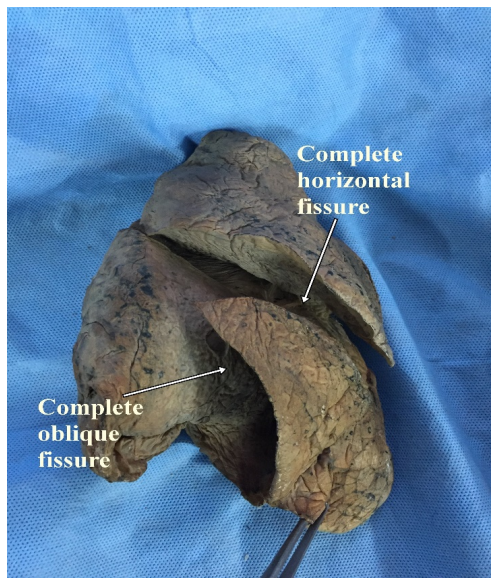

Figure 5. Right lung showing both oblique and horizontal fissures are complete.

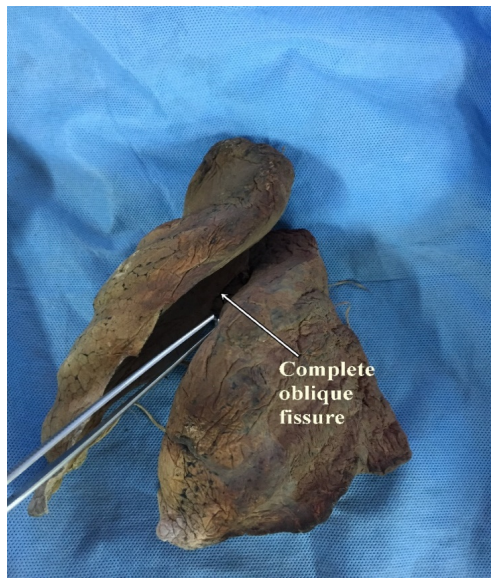

Figure 6. Left lung showing complete oblique fissure. 


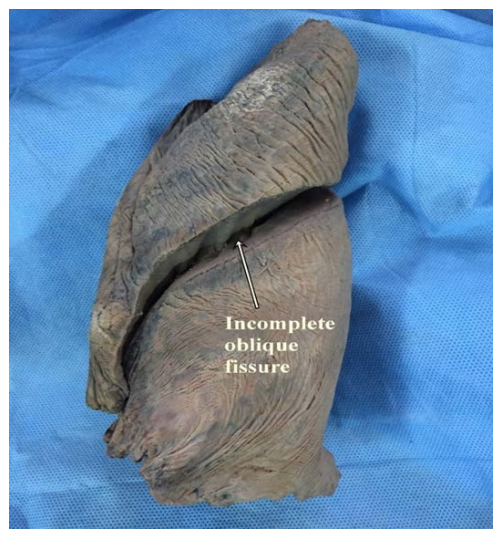

Figure 7. Left lung showing incomplete Oblique fissure.

Table 2. Incidences of variation in oblique, horizontal and accessory fissures in right and left lungs.

\begin{tabular}{cccccc}
\hline \multirow{2}{*}{ Lung specimen } & Fissures & \multicolumn{4}{c}{ No. of lungs (\%) } \\
\cline { 3 - 6 } & & Complete & Incomplete & Absent & Accessory \\
\hline \multirow{2}{*}{ Right lung N = 38 } & Oblique & $24(63.16)$ & $14(36.84)$ & - & $2(5.26)$ \\
& Horizontal & $18(47.37)$ & $16(42.11)$ & $4(10.53)$ & \\
Left lung N = 32 & Oblique & $21(55.26)$ & $11(34.38)$ & - & $12(37.5)$ \\
\hline
\end{tabular}

Accessory fissures were observed in 3 right lungs; out of which only the inferior accessory fissure observed in 2 (5.3\%) (Figure 8). Accessory fissures were observed in 12 left lungs (37.5\%) with all of them being left minor fissures (LMF) (Figure 9 and Figure 10). Observations of accessory fissures are summarized in Table 3.

Our findings using the Craig and Walker's classification (Table 3) demonstrate that $18(56.25 \%)$ left and $20(56.25 \%)$ right lung oblique fissures, together with $13(34.21 \%)$ of the horizontal fissure was classified as grade I. Three left lung (9.38\%) and 4 right lungs (10.53\%) oblique fissures together with 5 right lung (13.16\%) horizontal fissures were categorized as grade II. Grade III fissures were observed in 11 left lung (34.37\%) and 14 right lung (36.84\%) oblique fissures, together with 16 right lung $(42.11 \%)$ horizontal fissures. Only $4(10.53 \%)$ grade IV horizontal fissures were found in the right lungs.

\section{Discussion}

The lungs develop from the lung bud of the cranial foregut which subsequently differentiates into the various components of the respiratory tree and parenchyma. With progressive development, the lung bud grows caudally into the surrounding mesenchyme and bifurcates into right and left bronchial buds. The right bronchial bud then divides into three secondary bronchi while the left bud into two secondary bronchi. Each lung then develops by a process of repeated dichotomous branching of the secondary bronchi. After several generations of 


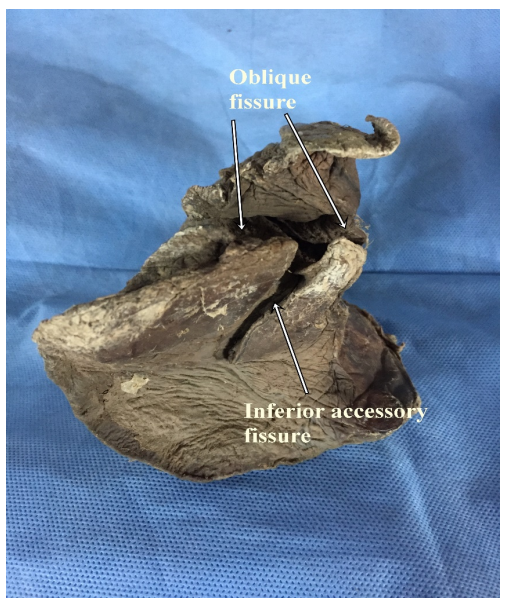

Figure 8. Basal surface of the Right lung showing inferior accessory fissure.

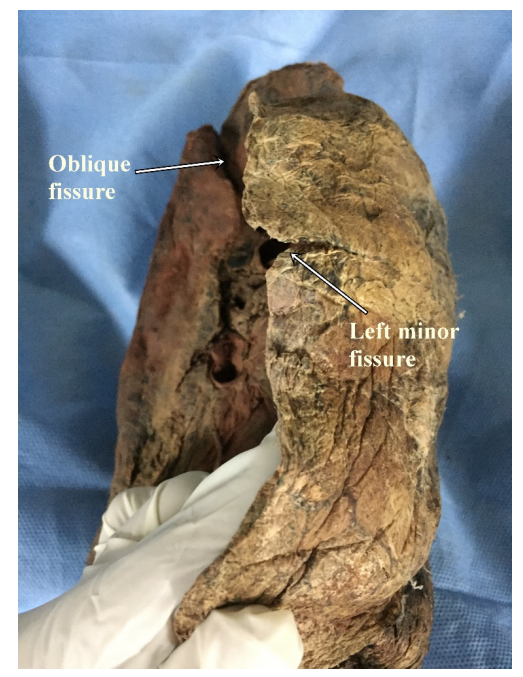

Figure 9. Costal surface of the left lung showing left minor fissure.

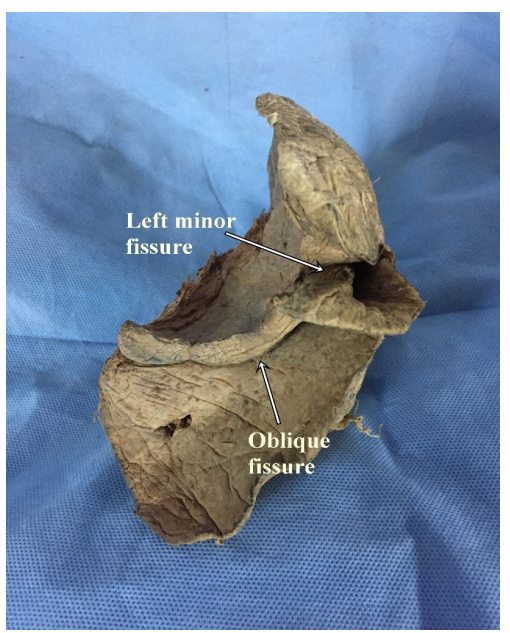

Figure 10. Left lung showing left minor fissure with Lingula appearing as a separate lobe. 
Table 3. Incidences of variation in accessory fissures in right and left lung.

\begin{tabular}{ccc}
\hline Accessory fissures & Right lung $\mathrm{n}=38$ & Left lung $\mathrm{n}=32$ \\
\hline Superior accessory fissure & - & - \\
Inferior accessory fissure & $2(5.26)$ & - \\
Left minor fissure & - & $12(37.5)$ \\
Azygous fissure & - & - \\
\hline
\end{tabular}

branching, bronchopulmonary segments are formed [17] [18]. In the early fetal period, bronchopulmonary segments are separated by spaces which later on get obliterated except along the division of principal bronchi giving rise to major fissures; that is, the oblique and horizontal in the right lung and the oblique fissure in the left [17] [18]. Variations in major fissures; that is, absence of or incomplete oblique and horizontal fissures are due to a complete or partial defect in the obliteration of these spaces along the division of principal bronchus [19]. An accessory fissure is the result of non-obliteration of spaces along bronchopulmonary segments that are normally obliterated [20].

Several authors have reported the anomalous fissures and lobes following the Craig and Walker [7] proposed fissural classification. Studies on the subject have been performed on different cadaveric populations and their findings are compared with the present study as shown in Table 4. Variation of the lung fissures is well reported with papers on cadaveric populations from Turkey [21], Ethiopia [15], Napalese [5], The United States [22] and India [1] [3] [14] [23]-[44].

The prevalence of the absence of horizontal fissures was comparatively more than the absence of oblique fissures in both the right and the left lung in all previous studies including the present study, with the exception of study reported by Bhardwaj et al. [44]. Similar to our study, the oblique fissure of right lung was reported to be absent in 14 out of the 24 studies, with the remaining researchers not finding any cases of missing oblique fissures. Absent oblique fissures of the left lung were reported in 13 out of 24 studies, including the present study. As observed from the different studies, an absent horizontal fissure is a commonly occurring variation (Table 4). The only study not to report a single case of an absent horizontal fissure was that by Mamatha et al. [43].

Other than variations in major (oblique and horizontal) fissures, radiologists and clinicians have to be aware of possibilities of having accessory fissures. In our study, LMF was found to be the most frequently occurring accessory fissure. This was consistent with findings by Sudikshya et al. and Çimen et al. [5] [34]. Grading of fissures is important in planning of pulmonary surgeries for easy approach in surgical procedure and to anticipate post-operative complications. For example, in cases of incomplete fissuration with resultant parenchymal fusion, more dissections may be required in order to reach the bronchi and pulmonary arteries during surgical resections leading to more hemorrhage and air leak [5] [45]. Therefore, knowledge of anatomical variations alerts the surgeons to potential complications that may be encountered during surgical intervention. 
Table 4. Comparison of different studies indicating the variations of oblique and horizontal fissures. Data is expressed as percentages.

\begin{tabular}{|c|c|c|c|c|c|c|c|c|c|}
\hline \multirow{3}{*}{$\begin{array}{l}\text { Study \& study } \\
\text { population }\end{array}$} & \multicolumn{6}{|c|}{ Right lung } & \multirow{2}{*}{\multicolumn{3}{|c|}{$\begin{array}{l}\text { Left lung } \\
\text { Oblique }\end{array}$}} \\
\hline & \multicolumn{3}{|c|}{ Oblique } & \multicolumn{3}{|c|}{ Horizontal } & & & \\
\hline & Complete & Incomplete & Absent & Complete & Incomplete & Absent & Complete & Incomplete & Absent \\
\hline $\begin{array}{c}\text { Medler (1947) [22] } \\
\text { United States }\end{array}$ & 69.6 & $\begin{array}{c}25.6 \\
(307 / 1200)\end{array}$ & $\begin{array}{c}4.8 \\
(58 / 1200)\end{array}$ & 37.7 & $\begin{array}{c}17.1 \\
(205 / 1200)\end{array}$ & $\begin{array}{c}45.2 \\
(506 / 1200)\end{array}$ & 82.1 & $\begin{array}{c}10.6 \\
(127 / 1200)\end{array}$ & $\begin{array}{c}7.3 \\
(88 / 1200)\end{array}$ \\
\hline $\begin{array}{c}\text { Lukose et al., } 1999 \\
\text { [23] India }\end{array}$ & 100 & 0 & 0 & 68.5 & $21(4 / 19)$ & $10.5(2 / 19)$ & 79 & $21(4 / 19)$ & 0 \\
\hline $\begin{array}{l}\text { Meenakshi et al., } \\
2004 \text { [24] India }\end{array}$ & 63.4 & $36.6(11 / 30)$ & 0 & 20.1 & $63.3(19 / 30)$ & $16.6(5 / 30)$ & 53.4 & $46.6(14 / 30)$ & 0 \\
\hline $\begin{array}{c}\text { Bergman et al., } 2008 \\
\text { [16] India }\end{array}$ & 70 & $30(83 / 277)$ & 0 & 12 & $67(186 / 277)$ & $21(58 / 277)$ & 70 & $30(83 / 277)$ & 0 \\
\hline $\begin{array}{l}\text { Bhardwaj et al., } \\
2010 \text { [44] India }\end{array}$ & 53.6 & $39.3(11 / 28)$ & $7.1(2 / 28)$ & 42.9 & $50(14 / 28)$ & $7.1(2 / 28)$ & 53.6 & $35.7(10 / 28)$ & $10.7(3 / 28)$ \\
\hline $\begin{array}{l}\text { Nene et al., } 2011 \\
\quad \text { [13] India }\end{array}$ & 92 & $6(3 / 50)$ & $2(1 / 50)$ & 78 & $8(4 / 50)$ & $14(7 / 50)$ & 88 & $12(6 / 50)$ & 0 \\
\hline $\begin{array}{c}\text { Dutta et al., } 2013 \\
\text { [14] India }\end{array}$ & 26.92 & 61.54 & 11.54 & 26.49 & 38.89 & 34.62 & 44 & 48 & 8 \\
\hline $\begin{array}{l}\text { Jacob and Pillay, } \\
2013 \text { [29] India }\end{array}$ & 46.6 & 50 & 3.4 & 10 & 83.4 & 6.6 & 61.1 & 38.9 & 0 \\
\hline $\begin{array}{c}\text { Quadros et al., } 2014 \\
\text { [34] India }\end{array}$ & 94.46 & $5.55(2 / 36)$ & 0 & 63.88 & $25(9 / 36)$ & $11.11(4 / 36)$ & 97.5 & $2.5(1 / 40)$ & 0 \\
\hline $\begin{array}{l}\text { Hema, } 2014[32] \\
\text { India }\end{array}$ & 90 & 10 & 0 & 82 & 8 & 10 & 90 & 8 & 2 \\
\hline $\begin{array}{l}\text { Varalakshmi et al., } \\
2014 \text { [35] India }\end{array}$ & 74.2 & 21 & 4.8 & 60 & 30 & 10 & 82.1 & 10.6 & 7.3 \\
\hline $\begin{array}{c}\text { George et al., } 2014 \\
{[31] \text { India }}\end{array}$ & 96.93 & 3.07 & 0 & 61.55 & 35.38 & 3.07 & 84.94 & 15.06 & 0 \\
\hline $\begin{array}{l}\text { Kaul et al., } 2014 \text { [33] } \\
\text { India }\end{array}$ & 68 & 24 & 8 & 28 & 32 & 40 & 60 & 40 & 0 \\
\hline $\begin{array}{l}\text { Magadum et al., } \\
2015 \text { [38] India }\end{array}$ & 30 & 60 & 10 & 35 & 52.5 & 12.5 & 50 & 42.5 & 7.5 \\
\hline $\begin{array}{c}\text { Divya et al., } 2015 \\
\text { [37] India }\end{array}$ & 89.3 & 10.7 & 0 & 28.6 & 50 & 21.4 & 77.8 & 14.8 & 7.4 \\
\hline $\begin{array}{c}\text { Anbusudar and } \\
\text { Dhivya, } 2016[41] \\
\text { India }\end{array}$ & 72 & 28 & 0 & 36 & 44 & 20 & 68 & 32 & 0 \\
\hline $\begin{array}{l}\text { Mamatha et al., } \\
2016 \text { [43] India }\end{array}$ & 85 & 15 & 0 & 50 & 50 & 0 & 65 & 35 & 0 \\
\hline $\begin{array}{l}\text { Sudikshya KC et al., } \\
2018 \text { [20] Nepal }\end{array}$ & 69.57 & 30.43 & 0 & 52.18 & 34.78 & 13.04 & 48.15 & 51.85 & 0 \\
\hline $\begin{array}{l}\text { Present study } \\
\text { Kenya, Africa }\end{array}$ & 63.16 & 36.84 & 0 & 47.37 & 42.11 & 10.53 & 55.26 & 34.38 & 0 \\
\hline
\end{tabular}

Patients with incomplete/lower pulmonary fissure development have a higher chance of tumor invasion, which would therefore be related to lung cancer prognosis and that fissures limit the spread of lung cancer. The degree of fissure de- 
velopment was found to be a prognostic factor in patients with resected stage I adenocarcinoma [46].

Accessory fissures, like the major fissures, not only serve as natural barriers against infection but are also useful in localizing focal pulmonary parenchymal disease and in differentiating pleural from parenchymal disease [47] [48]. Thus, identifying AF is important for precise localization of lesions and characterization of diseases [1].

The limitation of this study is failure of the study to investigate broncho-vascular abnormalities or variations associated with incomplete or accessory fissures. As authors of this study highlighted, these variations (incomplete fissure, or accessory fissure) may have a clinical implication, especially because of associated variations in pulmonary vessel (pulmonary artery, pulmonary vein), bronchial tree or even lymphatic drainage, which are critical in lung cancer surgery.

\section{Conclusion}

Knowledge of the anatomy and normal variants of the MF and AF is necessary for appreciation of gross lobar anatomy, provide useful information for recognizing their variable appearances on imaging, as well as the related abnormalities. In addition, being aware of these variations before pulmonary segmentectomy and lobectomy may inform and adjust the preoperative plans.

\section{Acknowledgements}

The authors sincerely thank those who donated their bodies to science so that anatomical research could be performed. Results from this research can potentially increase mankind's overall knowledge. Therefore, these donors and their families deserve our highest gratitude.

\section{Conflicts of Interest}

The authors declare no conflicts of interest.

\section{References}

[1] Ozmen, C.A., Nazaroglu, H., Bayrak, A.H., Senturk, S. and Akay, H.O. (2010) Evaluation of Interlobar and Accessory Pulmonary Fissures on 64-Row MDCT. Clinical Anatomy, 23, 552-558. https://doi.org/10.1002/ca.20971

[2] Standring, S. (2015) Gray's Anatomy International Edition: The Anatomical Basis of Clinical Practice. Elsevier Health Sciences, Amsterdam.

[3] Standring, S. (2020) Gray's Anatomy E-Book: The Anatomical Basis of Clinical Practice. Elsevier Health Sciences, Amsterdam.

[4] Muttikkal, T.J.E. and Deng, C. (2012) Non-Azygos Accessory Fissure in Right Upper Lobe Associated with Superior and Inferior Accessory Fissures in Right Lower Lobe. Journal of Clinical Imaging Science, 2, 79. https://doi.org/10.4103/2156-7514.105133

[5] Sudikshya, K.C., Shrestha, P., Shah, A.K. and Jha, A.K. (2018) Variations in Human Pulmonary Fissures and Lobes: A Study Conducted in Nepalese Cadavers. Anatomy 
\& Cell Biology, 51, 85. https://doi.org/10.5115/acb.2018.51.2.85

[6] Cronin, P., Gross, B.H., Kelly, A.M., Patel, S., Kazerooni, E.A. and Carlos, R.C. (2010) Normal and Accessory Fissures of the Lung: Evaluation with Contiguous Volumetric Thin-Section Multidetector CT. European Journal of Radiology, 75, e1-e8. https://doi.org/10.1016/j.ejrad.2009.10.009

[7] Craig, S.R. and Walker, W.S. (1997) A Proposed Anatomical Classification of the Pulmonary Fissures. Journal of the Royal College of Surgeons of Edinburgh, 42, 233-234.

[8] Rosse, C. and Gaddum-Rosse, P. (1997) Hollinshead's Textbook of Anatomy. Lippincott Williams \& Wilkins, Philadelphia.

[9] Berhe, A.G., Ekanem, P. and Beyene, H.A. (2016) Variation of Fissure and Lobar Pattern of Lung: A Case Report.

[10] Tarver, R.D. (1995) How Common Are Incomplete Pulmonary Fissures, and What Is Their Clinical Significance? AJR. American Journal of Roentgenology, 164, 761-761. https://doi.org/10.2214/ajr.164.3.7863909

[11] Sciurba, F.C., Ernst, A., Herth, F.J., Strange, C., Criner, G.J., Marquette, C.H., Kovitz, K.L., Chiacchierini, R.P., Goldin, J. and Mclennan, G. (2010) A Randomized Study of Endobronchial Valves for Advanced Emphysema. The New England Journal of Medicine, 363, 1233-1244. https://doi.org/10.1056/NEJMoa0900928

[12] Koster, T.D. and Slebos, D.-J. (2016) The Fissure: Interlobar Collateral Ventilation and Implications for Endoscopic Therapy in Emphysema. International Journal of Chronic Obstructive Pulmonary Disease, 11, 765. https://doi.org/10.2147/COPD.S103807

[13] Nene, A.R., Gajendra, K.S. and Sarma, M.V.R. (2011) Lung Lobes and Fissures: A Morphological Study. Journal of Experimental and Clinical Anatomy, 5, 30-38. https://doi.org/10.2399/ana.10.005

[14] Dutta, S., Mandal, L., Mandal, S.K., Biswas, J., Ray, A. and Bandopadhyay, M. (2013) Natural Fissures of Lung: Anatomical Basis of Surgical Techniques and Imaging. National Journal of Medical Research, 3, 117-121.

[15] Gebregziabher, A., Berhe, T. and Ekanem, P. (2015) Variations of Fissures and Lobes of the Lungs in Human Cadavers in Selected Universities of Ethiopia. International Journal of Pharmaceutical Sciences and Research, 6, 981-990.

[16] Bergman, R.A., Afifi, A.K. and Miyauchi, R. (2008) Variations in Peripheral Segmentation of Right Lung and the Base of the Right and Left Lungs.

[17] Sadler, T.W. (2011) Langman's Medical Embryology. Lippincott Williams \& Wilkins, Philadelphia.

[18] Moore, K.L., Persaud, T.V.N. and Torchia, M.G. (2018) The Developing Human EBook: Clinically Oriented Embryology. Elsevier Health Sciences, Amsterdam.

[19] Modgil, V., Das, S. and Suri, R. (2006) Anomalous Lobar Pattern of Right Lung: A Case Report. International Journal of Morphology, 24, 5-6. https://doi.org/10.4067/S0717-95022006000100001

[20] Larsen, W.J. (1998) Essentials of Human Embryology. Churchill Livingstone, New York.

[21] Dogan, N.U., Uysal, I.I., Demirci, S., Dogan, K.H. and Kolcu, G. (2015) Major Anatomic Variations of Pulmonary Fissures and Lobes on Postmortem Examination. Acta Clinica Croatica, 54, 201-206.

[22] Medlar, E.M. (1947) Variations in Interlobar Fissures. The American Journal of Roentgenology and Radium Therapy, 57, 723-725.

[23] Lukose, R., Paul, S., Daniel, M., Abraham, S.M., Alex, M.E., Thomas, R. and Nair, V. (1999) Morphology of the Lungs: Variations in the Lobes and Fissures. Biomedicine- 
Trivandrum Then Taramani, 19, 227-232.

[24] Meenakshi, S., Manjunath, K.Y. and Balasubramanyam, V. (2004) Morphological Variations of the Lung Fissures and Lobes. The Indian Journal of Chest Diseases \& Allied Sciences, 46, 179-182.

[25] Prakash, A.K.B., Krishna, G.G., Suma, H.Y. and Shashirekha, M. (2010) Lung Morphology: A Cadaver Study in Indian Population. Italian Journal of Anatomy and Embryology, 115, 235-240.

[26] Devi, N.B., Rao, B.N. and Sunitha, V. (2011) Morphological Variations of Lung-A Cadaveric Study in North Coastal Andhra Pradesh. International Journal of Biological and Medical Research, 2, 1149-1152.

[27] Murlimanju, B.V., Prabhu, L.V., Shilpa, K., Pai, M.M., Kumar, C.G., Rai, A. and Prashanth, K.U. (2012) Pulmonary Fissures and Lobes: A Cadaveric Study with Emphasis on Surgical and Radiological Implications. Clinical Therapeutics, 163, 9-13.

[28] Ghosh, E., Basu, R., Dhur, A., Roy, A., Roy, H. and Biswas, A. (2013) Variations of Fissures and Lobes in Human Lungs-A Multicentric Cadaveric Study from West Bengal, India. International Journal of Anatomy Radiology and Surgery, 2, 5-8.

[29] Jacob, S.M. and Pillay, M. (2013) Variations in the Inter-Lobar Fissures of Lungs Obtained from Cadavers of South Indian Origin. International Journal of Morphology, 31, 497-499. https://doi.org/10.4067/S0717-95022013000200022

[30] Kommuru, H., Sree, L.D., Hema, P.J. and Swayam, J.S. (2013) Pulmonary Fissures and Lobar Variations in Relation to Surgical \& Radiological Implications. IOSR Journal of Dental and Medical Sciences, 5, 51-54. https://doi.org/10.9790/0853-0515154

[31] George, B.M., Nayak, S.B. and Marpalli, S. (2014) Morphological Variations of the Lungs: A Study Conducted on Indian Cadavers. Anatomy \& Cell Biology, 47, 253-258. https://doi.org/10.5115/acb.2014.47.4.253

[32] Hema, L. (2014) Lungs Lobes and Fissures: A Morphological Study. International Journal of Recent Trends in Science and Technology, 11, 122-126.

[33] Kaul, N., Singh, V., Sethi, R. and Kaul, V. (2014) Anomalous Fissures and Lobes of Human Lungs of North Indian Population of Western UP. Journal of the Anatomical Society of India, 63, S26-S30. https://doi.org/10.1016/j.jasi.2014.08.002

[34] Quadros, L.S., Palanichamy, R. and D’Souza, A.S. (2014) Variations in the Lobes and Fissures of Lungs-A Study in South Indian Lung Specimens. European Journal of Anatomy, 18, 16-20.

[35] Varalakshmi, K.L., Jyothi, N.N. and Sangeetha, M. (2014) Morphological Variations of Fissures of Lung. Indian Journal of Applied Research, 4, 457-469. https://doi.org/10.15373/2249555X/August2014/120

[36] Zareena, S.K. (2014) A Study of Morphology and Variations of Lungs in Adults and Foetus. International Journal of Advancements in Research \& Technology, 3, 150-157.

[37] Divya, C., Venkateshu, K.V. and Swaroop Raj, B.V. (2015) Anatomical Study of Pulmonary Fissures and Lobes. International Journal of Recent Scientific Research, 6, 4554-4557.

[38] Magadum, A., Dixit, D. and Bhimalli, S. (2015) Fissures and Lobes of Lung-An Anatomical Study and Its Clinical Significance. International Journal of Current Research and Review, 7, 8.

[39] Radha, K. and Durai Pandian, K. (2015) Fissures and Lobes of Lungs: A Morphological and Anatomical Study. International Journal of Anatomy and Research, 2, 995-998. https://doi.org/10.16965/ijar.2015.139

[40] Wahane, A. and Satpute, C. (2015) A Cadaveric Study of Morphological Variations of Lung in Vidarbha Region. International Journal of Science and Research (Raipur), 
4, 2163-2166.

[41] Anbusudar, K. and Dhivya, S. (2016) Anatomical Study on Variations of Fissures of Lung. Indian Journal of Clinical Anatomy and Physiology, 3, 449-451. https://doi.org/10.5958/2394-2126.2016.00102.X

[42] Dhanalakshmi, V., Manoharan, C., Rajesh, R. and Ananthi, K.S. (2016) Morphological Study of Fissures and Lobes of Lungs. International Journal of Anatomy and Research, 4, 1892-1895. https://doi.org/10.16965/ijar.2016.104

[43] Mamatha, Y., Murthy, C.K. and Prakash, B.S. (2016) Study of Morphological Variations of Fissures and Lobes of Lung. International Journal of Anatomy and Research, 4, 1874-1877. https://doi.org/10.16965/ijar.2016.105

[44] Bhardwaj, A.K., Shashirekha, M., Suma, H.Y., Krishna, G.G. and Singh, G. (2010) Lung Morphology: A Cadaver Study in Indian Population. Italian Journal of Anatomy and Embryology, 115, 235-240.

[45] Çimen, M., Erdil, H. and Karatepe, T. (2005) A Cadaver with Azygos Lobe and Its Clinical Significance. Anatomical Science International, 80, 235-237.

https://doi.org/10.1111/j.1447-073X.2005.00116.x

[46] Lee, S., Lee, J.G., Lee, C.Y., Kim, D.J. and Chung, K.Y. (2016) Pulmonary Fissure Development Is a Prognostic Factor for Patients with Resected Stage I Lung Adenocarcinoma. Journal of Surgical Oncology, 114, 848-852.

https://doi.org/10.1002/jso.24438

[47] Godwin, J.D. and Tarver, R.D. (1985) Accessory Fissures of the Lung. American Journal of Roentgenology, 144, 39-47. https://doi.org/10.2214/ajr.144.1.39

[48] Berkmen, T., Berkmen, Y.M. and Austin, J.H. (1994) Accessory Fissures of the Upper Lobe of the Left Lung: CT and Plain Film Appearance. AJR. American Journal of Roentgenology, 162, 1287-1293. https://doi.org/10.2214/ajr.162.6.8191982 